\title{
Association of Brain Damage with Therapeutic Abortion Induced by Amniotic-Fluid Replacement : Report of Two Cases
}

\author{
J. M. CAMERON,** M.D., PH.D., M.C.PATH., D.M.J. ; A. D. DAYAN,*† M.B., B.SC., M.R.C.P., M.C.PATH.
}

[With Special Plate]

Brit. med. F., 1966, 1, 1010-1013

Recently amniotic-fluid replacement by the intrauterine injection of strongly hypertonic solutions has been used increasingly often to produce therapeutic abortions or to induce labour when the foetus is already known to be dead (Csapo, 1961 ; Wood, Booth, and Pinkerton, 1962). Few complications of the method have been reported, though it has been tried and discarded by other workers because of the risk of intrauterine sepsis (Peel, 1935). Two cases are reported in which widespread cerebral infarction occurred after the procedure and in which it was possible that the strongly hypertonic solutions employed were responsible for the brain damage.

\section{Case 1}

A previously healthy 20-year-old secretary was advised, on psychiatric grounds, to have a therapeutic abortion in the 20th week of her first pregnancy. The operation was performed under local anaesthesia by inserting a fine trocar and cannula through the anterior abdominal and uterine walls into the amniotic cavity, removing about $200 \mathrm{ml}$. of amniotic fluid, which was lightly bloodstained, and injecting manually approximately $400 \mathrm{ml}$. of sterile $20 \%$ sodium chloride solution. She appeared well immediately afterwards, but complained of a burning sensation in her finger-tips. After about four hours her condition deteriorated, and she began to have epileptiform fits. About 12 hours after the operation her blood-pressure was said to be normal. Sedatives were given parenterally as symptomatic treatment, but she suddenly stopped breathing and died some 22 hours after the intrauterine injections. A dead foetus had been delivered 12 hours after the intra-amniotic injection. Twelve hours after the amniocentesis serum electrolytes were: chlorides $143 \mathrm{mEq} / 1$., sodium $174 \mathrm{mEq} / 1$, potassium 3.7 $\mathrm{mEq} / \mathrm{l}$., urea $26 \mathrm{mg} . / 100 \mathrm{ml}$.

Necropsy showed evidence of the recent pregnancy. In the anterior wall of the fundus of the uterus there were two puncture wounds which appeared to have penetrated through the placental bed. The brain on removal appeared to be slightly oedematous, and no subdural or subarachnoid haemorrhages were seen. The lungs showed patchy collapse. The cardiovascular system seemed to be normal and there was no evidence of air embolism. There was no peritonitis, nor any excess of fluid or blood in the peritoneal cavity. The kidneys appeared normal. The foetus and placenta were not available for examination.

\section{Microscopical Examination of Viscera}

Sections of heart, lungs, kidneys, liver, and spleen showed no histological abnormality. Pregnancy changes were seen in the pituitary, the breasts were active, and trophoblastic tissue was seen at the placental site in the uterus.

\section{Brain and Spinal Cord}

After fixation the brain was cut in coronal slices. These showed symmetrical haemorrhagic softenings of both amygdaloid nuclei, sparing only a thin rim supero-medially, and similar softening of the adjacent parts of both the right and left uncus (Special Plate, Fig. 1). The inferior parts of both claustra and the adjacent insular cortex were haemorrhagic. Other parts of the cerebrum appeared normal. There was a $\mathrm{Y}$-shaped haemorrhage $2 \mathrm{~cm}$. long in the pons, occupying the tegmental region and the ventral part of the median raphe (Special Plate, Fig. 2). The upper medulla appeared normal, but the region of the facial tubercles was congested. The cerebellum appeared normal, as did the spinal cord externally and after cutting transverse sections.

The distribution of lesions seen histologically in the brain is shown diagrammatically in Fig. 3 (Special Plate), where dotted areas represent the damaged parts. The appearances were similar at all the sites examined. Areas of acute selective neuronal necrosis shown by pyknosis and commercing fragmentation were present in sections from the frontal and more anterior parts of the parietal cortex (Special Plate, Fig. 6), but not from the occipital cortex or the posterior parts of the parietal lobes. These lesions were usually found at the crests of gyri and commonly were isolated, though a pseudo-laminar distribution was seen in a few areas. The adjacent white matter appeared normal. In both amygdaloid nuclei there was almost total haemorrhagic infarction (Special Plate, Fig. 7), and similar but less extensive necrosis of neurones and glial cells was seen in the head of the caudate nuclei, ansa lenticularis, and globus pallidus on both sides. The end-plate region and Somner's $h_{1}$ section of Ammon's horn were damaged bilaterally, as well as the grey matter of the adjacent anterior end of the lingual gyrus. The tegmentum and median raphe of the pons showed severe haemorrhagic infarction (Special Plate, Fig. 8), and there were less intense symmetrical lesions in the dorsal part of the medulla involving the region of the tractus solitarius and medial vestibular nuclei as far down as the level of the dorsal decussation. In affected areas myelin sheaths appeared to be forming balloons and to be fragmenting, and silver stains showed similar damage to axons. Blood-vessels everywhere appeared normal apart from some margination of polymorphs in capillaries in necrotic areas and pools of protein-rich oedema fluid about capillaries near them.

Sections of the spinal cord and its anterior and posterior roots at all levels appeared normal. No lesions were seen in the spinal dura and extradural venous plexus.

\section{Case 2}

A 20-year-old student teacher in good physical health was recommended, after psychiatric examination, for a therapeutic abortion in the 20th week of her first pregnancy. Amniocentesis was carried out under general anaesthesia by aspirating $200 \mathrm{ml}$. of amniotic fluid and injecting in its place $150 \mathrm{ml}$. of $30 \%$ sodium chloride solution. She never fully regained consciousness, though one hour after the operation she appeared to respond to painful stimuli. One hour later she had the first of several generalized convulsions, which occurred at varying intervals. Her temperature was raised, she was stuporous, responding to painful stimuli, and had a spastic cog-wheel rigidity in all four limbs on passive movement. The plantar reflexes became extensor after 24 hours. There was sludging of red cells in the retinal veins on the right side. The disc margins were distinct and there was no papilloedema. Lumbar puncture, 25 hours post-operatively, showed normal pulsation of a clear

\footnotetext{
* Department of Forensic MeJicine and the Institute of Pathology, London Hospital.

† Present address: Department of Pathology, General Hospital, Southampton.
} 


\section{J. M. CAMERON AND A. D. DAYAN: THERAPEUTIC ABORTION}
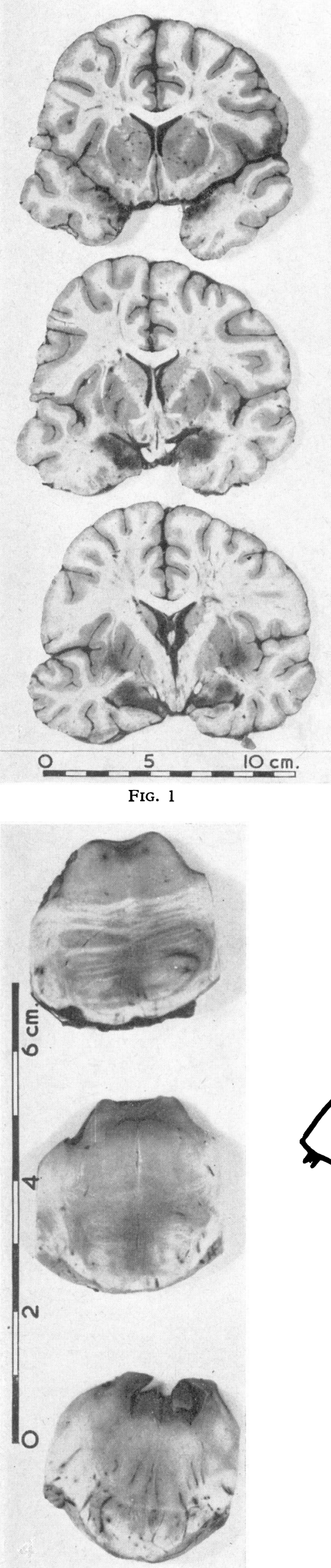

FIG. 4
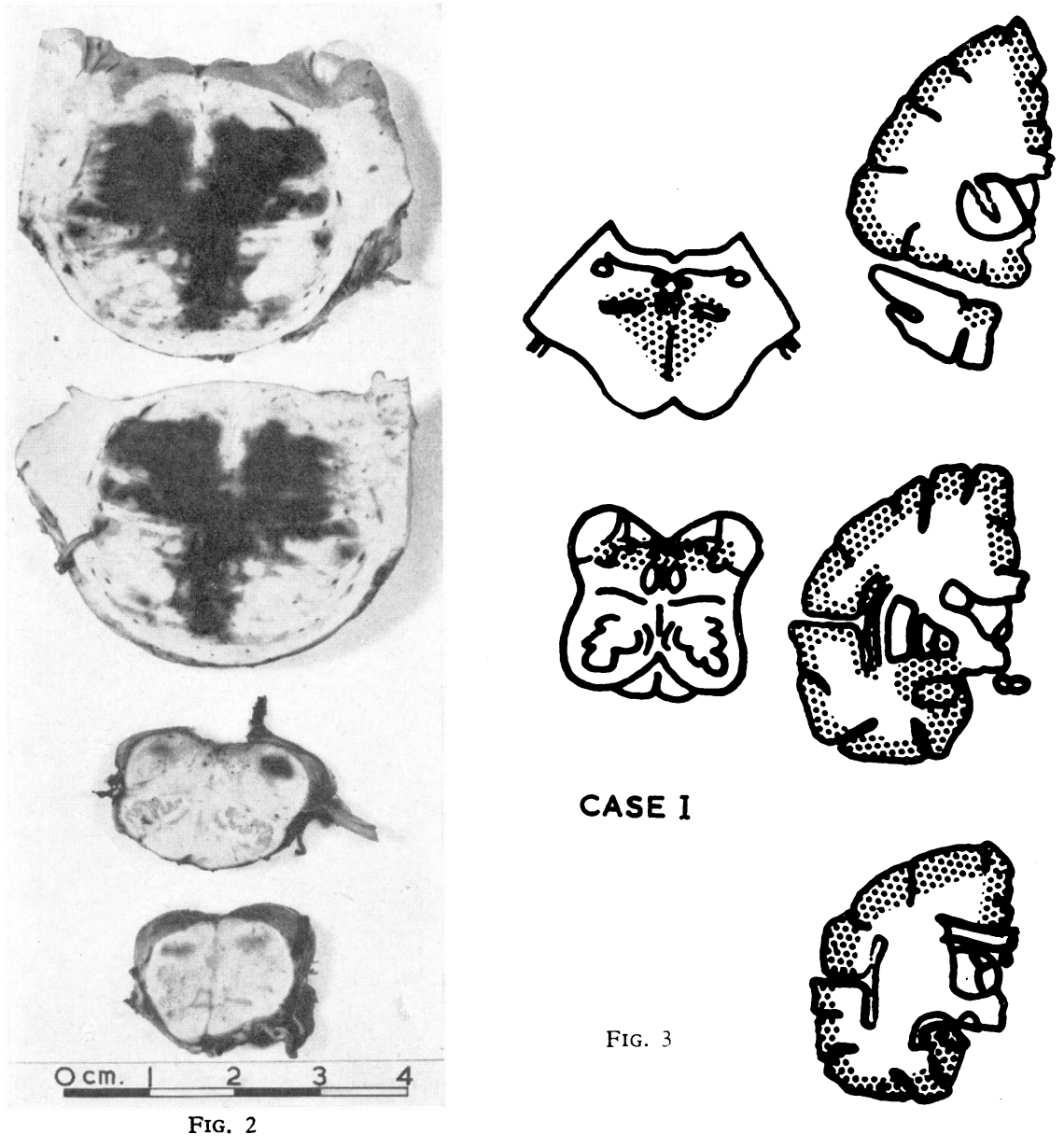

CASE I

FIG. 3

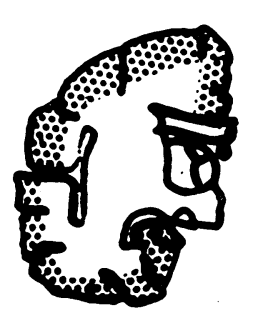

FIG 1-Case 1. Coronal slices of brain showing haemorrhagic infarction of both amygdaloid nuclei and the adjacent parts of the temporal lobes.

FIG. 2.-Case 1. Transverse slices of the pons and medulla. There are haemorrhagic infarcts in the tegmentum and the pes pontis and discrete foci of necrosis in the region of the vestibular nuclei on both sides.

FIG. 3.-Case 1. Diagrammatic representation of the distribution of the lesions in the brain.

FIG. 4.-Case 2. Discoloration about median raphe of pons. FIG. 5.-Case 2. Diagram to show the dis-
tribution of lesions in the brain.

\section{CASE II}

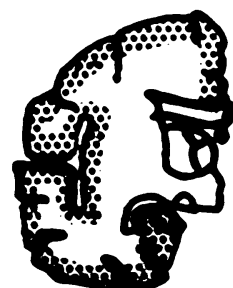




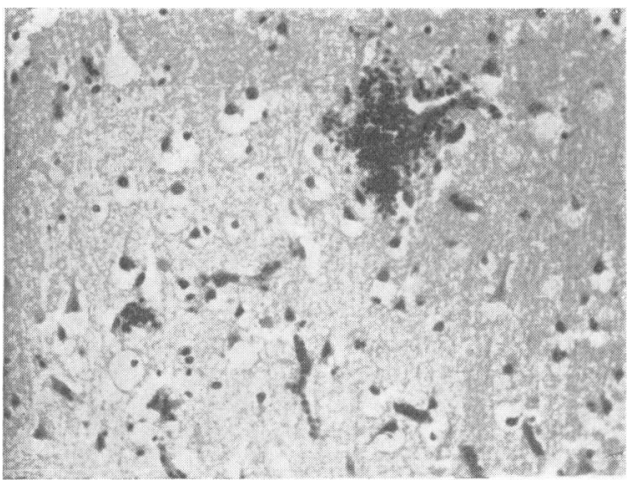

FIG. 6.-Case 1. Parietal cortex with small haemorrhages and pyknotic neurones. (Haemalum and eosin. $\times 320$.)

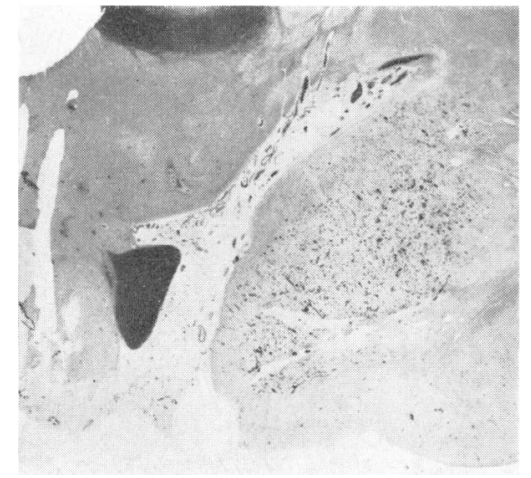

FIg. 7.-Case 1. Haemorrhagic infarction of right amygdaloid nucleus. (Loyez.

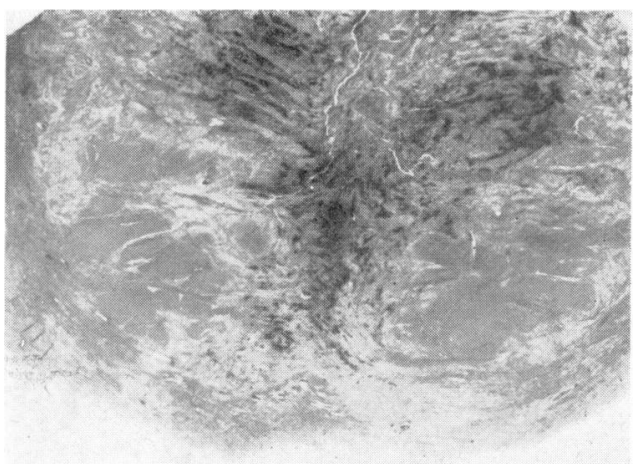

FIG. 8.-Case 1. Infarction of pes pontis. (H. and $\mathrm{E} . \quad \times 2$.)

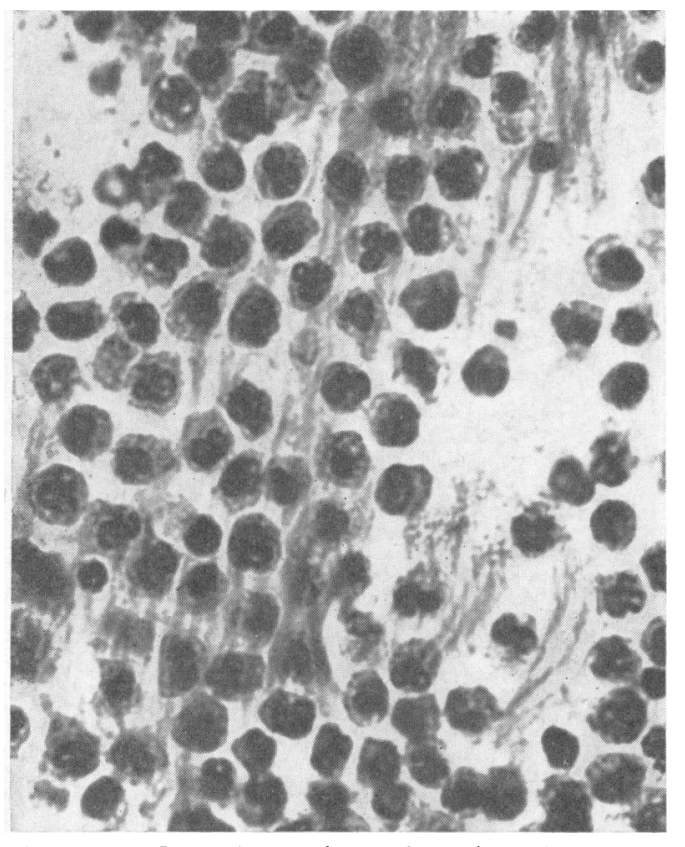

Fig. 11.-Case 2. Polymorphonuclear leucocytes cuffing a vessel in the median raphe of the pons. (H.

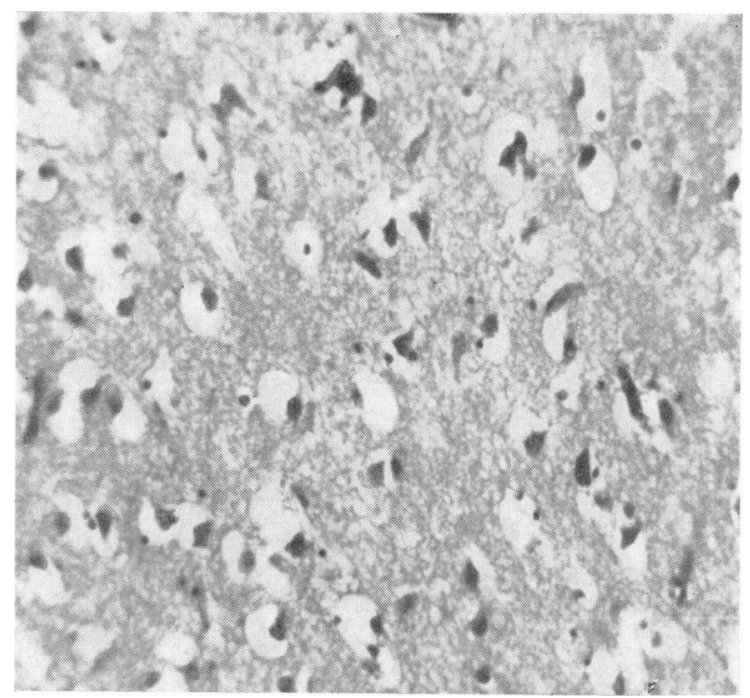

Fig. 10.-Case 2. Acute neuronal necrosis in the temporal cortex. $(H$. and E. $\times 400$.)

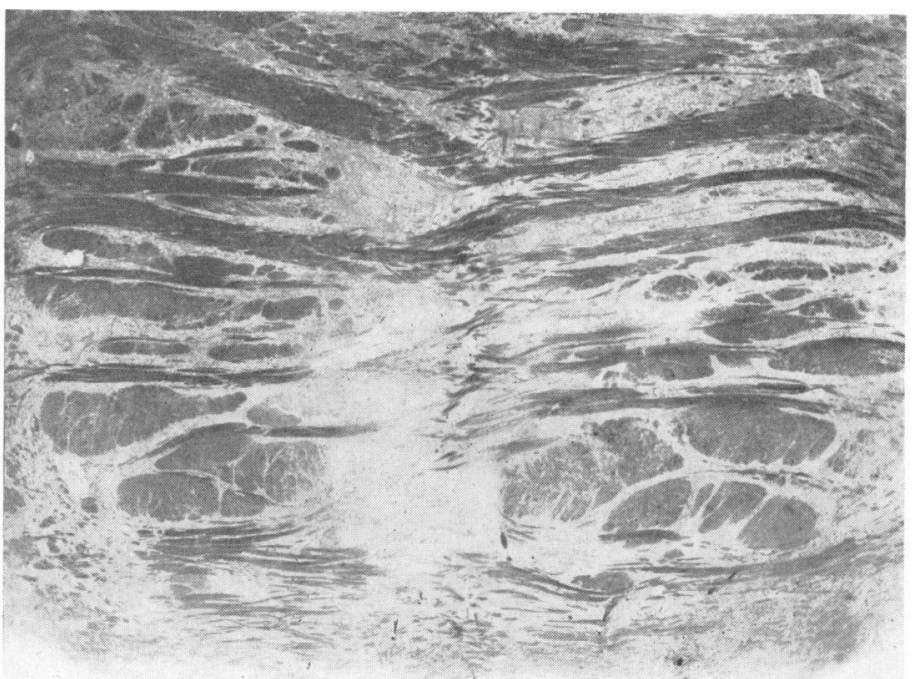

FIG. 12.-Case 2. Pallor of staining of myelin in middle of pes pontis. (Loyez. $\times 6$.) and E. $\times 640$.) 
yellow fluid at a pressure of $180 \mathrm{~mm}$. $\mathrm{H}_{2} \mathrm{O}$. It contained 5 lymphocytes/c.mm., and had a protein level of $1,000 \mathrm{mg} . / 100 \mathrm{ml}$. Slight haematuria and albuminuria was noted in the concentrated urine obtained by catheterization at this time.

Shortly before death the membranes were ruptured and a dead foetus and placenta were delivered. The patient died 45 hours after the operation, her condition having remained unchanged for the previous 24 hours.

Necropsy showed evidence of recent delivery. There were multiple puncture wounds in the anterior wall of the uterus. The brain was slightly ocdematous, and no major subdural or subarachnoid haemorrhages were seen. There were bilateral pleural effusions and a peritoneal exudate (approximately $400 \mathrm{ml}$. in each cavity). The cardiovascular system appeared normal, and there was no evidence of air embolism. The remaining organs appeared healthy.

\section{Microscopical Examination of Viscera}

The lungs were congested and oedematous, and there was a small amount of agonal vomitus in the bronchi, with patchy collapse and a low-grade inflammatory reaction. Occasional hyaline casts were seen in the renal tubules. In other viscera, apart from congestion, no abnormality was found.

\section{Brain and Spinal Cord}

After fixation the brain was moderately tense and showed some symmetrical uncinate grooving but no definite tonsillar herniation. The leptomeninges were deeply congested, particularly over the convexity of the cerebral hemispheres, and showed a few tiny subarachnoid haemorrhages.

Coronal sections of the cerebral hemispheres showed central discoloration and softening in both amygdaloid nuclei (Special Plate, Fig. 9). Ill-defined discoloration was also present in the uncus and in Ammon's horn on both sides. Patchy softening of the cerebral cortex was most conspicuous in the frontal lobes, particularly on the medial surfaces. Transverse sections of the brainstem revealed a strip of greyish discoloration in the pes pontis in the neighbourhood of the central raphe (Special Plate, Fig. 4). Dorsally it merged into an ill-defined greyish area in the tegmentum which continued caudally into the medulla. Sagittal sections of the cerebellum showed a discoloration of the deeper parts of the folia, particularly in the vermis. The spinal cord appeared normal externally and on transverse section.

Microscopical examination of the brain showed symmetrical lesions resembling those seen in Case 1. Their distribution is represented in Fig. 5 (Special Plate). The cortex of the frontal, parietal, and temporal lobes showed widespread acute neuronal necrosis, most marked at the crests of gyri (Special Plate, Fig. 10) and often associated with microscopic haemorrhages. In a few areas, such as the parietal cortex, occasional geographical areas of pseudo-laminar necrosis were present, but the commonest findings were of scattered eosinophilic and pyknotic neurones and of congested capillaries, many of which contained marginated polymorphs. The occipital lobes were not affected. In the amygdaloid nuclei on both sides there was very extensive neuronal necrosis and small haemorrhages and perivascular oedema, but no total infarction as seen in Case 1. The adjacent lingual gyri and claustrum were affected to a lesser extent. No damage was found in the basal ganglia. There was marked neuronal destruction and some oedema in the dorso-medial nuclei of the thalamus. In Ammon's horn eosinophilic and pyknotic neurones were found in the end-plate and Sommer's $h_{1}$ sector throughout its length. Similar lesions were present in the $h_{5}$ sector and the adjacent parts of the dentate gyrus which were associated with capillary haemorrhages.

In the brain-stem most blood-vessels were congested, and midline perforating branches of the basilar artery in the pes pontis at the level of the locus coeruleus were cuffed by polymorphonuclear leucocytes (Special Plate, Fig. 11). Loyez-stained preparations showed pallor of myelin staining in the midline at this level (Special Plate, Fig. 12). There was also acute neuronal necrosis in the nuclei of the pes pontis and reticular formation. At lower levels selective damage to neurones, with the development of vacuoles about the degenerating cell bodies, was seen in the medial and spinal vestibular nuclei and in both hypoglossal nerve nuclei. At the caudal limits of the inferior olives, vacuolation and pyknosis of neurones was marked in the region of the lateral reticular nuclei and in the spinal tract of the trigeminal nerve. In the dorsal part of the inferior medulla several structures were damaged, including the dorsal motor nucleus of the vagus, the cuneate and gracile nuclei, and the spinal tract of the trigeminal nerve. The cerebellum showed oedema of the granular layer, which is often considered to be a post-mortem artefact. The spinal cord appeared normal throughout its length.

\section{Discussion}

The cerebral damage found in these patients, in accordance with the clinical history, appears histologically to be of not more than 24 to 48 hours' duration. 'The lesions have a roughly symmetrical distribution, suggesting that they might have been caused by hypotension or by some systemic metabolic or toxic disturbance.

Systemic hypotension may produce "geographical" and pseudo-laminar necroses in the cerebral cortex which sometimes are associated with damage to the basal ganglia and cerebellum (reviewed by Meyer, 1963). There was no direct evidence of a hypotensive episode in either of the present patients. At necropsy the most marked lesions were in the amygdaloid nuclei, the pons, and the lateral parts of the medulla, whereas the cerebral cortex and basal ganglia were relatively less severely affected. Also, definite lesions were not found in the cerebellum of either patient. There appears to be no record of a proved case of hypotensive brain damage in which the distribution of the lesions has resembled that found in these two patients. It seems unlikely, therefore, that generalized arterial hypotension could have been the cause of the brain damage found in our two patients.

It is more likely that the cerebral infarction was due to some effect on the brain of the large volumes of strongly hypertonic solutions which had been injected into the amniotic cavity. Since the work of Weed and McKibben (1919-20) it has been known that hypertonic solutions of saline or dextrose, when injected intravenously, may cause a fall in the cerebrospinal fluid (C.S.F.) pressure and make the brain shrink. Cushing and Foley (1920) made similar observations in man and showed that oral administration of a concentrated solution had the same effect. The mode of action is thought to be extraction of water from the brain and C.S.F. by the hypertonic blood, from which they are separated by an effectively semipermeable membrane. However, Browder (1930) and Milles and Hurwitz (1932) reported that the abnormally low C.S.F. pressure produced in such a fashion increased after a few hours and might even come to exceed the normal level by a considerable amount. Similar observations have been made by more recent workers, who have observed increases of pressure up to $180 \%$ of control levels (Stubbs and Pennybacker, 1960 ; Rosomoff, 1962 ; Nash, Orth, and Smolik, 1965). This "rebound" rise in pressure is attributed to the slow mass movement of solutes across the blood-brain barrier. The brain-fluid compartments are still hypertonic when the blood has returned to its normal tonicity, and the rapid entry of water into the cerebral-fluid compartments causes the rise in pressure.

If this series of events had occurred in our two patients, then some of the lesions could be secondary to the raised intracranial pressure. The time of onset of symptoms is compatible with the delay required for this rebound rise in pressure. It was about four hours in Case 1 and some two hours in Case 2, and both patients might already have been slightly dehydrated by the usual practice of withholding fluids before any general anaesthetic is given. We assume that an intra-amniotic pool of $20 \%$ saline would be as effective in rendering the blood hypertonic as is oral or direct intravenous administration. If the brain had become swollen the infarction of the amygdaloid nuclei and adjacent structures would be attributed to compression of the anterior choroidal artery by 
downward displacement of the uncus through the tentorial opening (Lindenberg, 1955). Though no deep uncinate grooves were found at necropsy, sufficient time had elapsed before death for the cerebral oedema to have disappeared. Also, both patients had been given intravenous infusions of hypotonic and isotonic fluids, which would tend to relieve the osmotic imbalance. The second patient was probably given such treatment at a much earlier stage than the first, and this may account for the difference in the severity of the lesions in the two cases. The pontine damage is unlikely to be due to such secondary arterial insufficiency, because its Y-shape does not conform to the usual midline distribution of the lesions found in such cases. Extension into the medulla is exceedingly rare for secondary damage of this kind, and even then it does not usually pick out discrete nuclear groups, as was seen in both cases.

Epileptic convulsions may cause diffuse lesions in the amygdaloid nuclei and adjacent structures (Meyer, Beck, and Shepherd, 1955), but these were of selective neuronal necrosis only. They resembled the findings in Case 2, but were quite unlike the total infarction seen in Case 1 . The widespread cortical lesions in Case 2 also resemble those described in a fatal case of epilepsy by Small and Woolf (1957). The damage to the pons and medulla in both of the present cases had not been found after epileptic fits. It is unlikely, therefore, that all the damage could be secondary to the convulsions. The second patient was noticed to have "sludging" of the blood in her retinal veins some 24 hours after the amniocentesis. At this late stage in her illness it is impossible to be certain of the significance of this observation, and it cannot be taken to mean increased viscosity of the blood due to hypovolaemia produced by dehydration.

\section{Brain Damage in Other Clinical Conditions}

We have been unable to find any reports of cases comparable to the present ones. Other clinical conditions in which brain damage has been associated with hypertonicity of the extracellular-fluid compartment have been reported by Finberg, Kiley, and Lutterell (1963). They described an incident in which 14 infants were given artificial feeds made up with salt instead of sugar. Necropsies were done on five of the six babies who died; these showed widespread capillary haemorrhages in the brain, subdural and subarachnoid haemorrhages, and thrombosis of the major dural sinuses. Finberg (1959) discussed seven other reported cases of salt-poisoning in infants and noted that similar pathological changes had occurred. Cases have been reported in which patients have become dehydrated because of gastro-enteritis or mismanaged régimes of intravenous fluids and gastric suction, so producing more complex deficiencies of water and electrolytes. Crome (1952) found widespread focal scars in the cortex, gliosis in the putamen and outer globus pallidus, and diffuse gliosis throughout the brain-stem of a child aged 25 weeks who died after severe dehydration due to enterocolitis. Hallevorden and Meyer (1956) reported a similar case of a 6-months-old baby who collapsed with enterocolitis and was found later to have diffuse cortical scarring, état marbré of the putamen, and lobular sclerosis of the cerebellum.

Mérei (1960), Métraux and Binswanger (1963), and Ludwig (1963) have described adult patients dying in a state of severe dehydration, who were found at necropsy to have widespread petechiae throughout the cerebral hemispheres and cerebellum. Most of these patients also had scattercd necroses in the cerebral cortex and sometimes in the basal ganglia and cerebellum. Ludwig's case also had bilaterally symmetrical haemorrhages resembling those found in the medulla of our own cases, and Mérei's patient showed damage in the region of the vestibular nuclei, as in both the present cases. In fatal cases serum sodium levels have been estimated at various times before or after the onset of cerebral symptoms, and the reported levels are shown in the Table.

Plasma Sodium concentrations in Reported Cases of Fatal Dehydration with Brain Damage

\begin{tabular}{|c|c|c|c|c|}
\hline Author & & & Date & $\begin{array}{l}\text { Plasma Sodium } \\
\text { Concentrations }\end{array}$ \\
\hline $\begin{array}{l}\begin{array}{l}\text { Skinner and Moll } \\
\text { Finberg }\end{array} \text {.. } \\
\text { Ludwig } \quad . \\
\text { Métraux and Binswanger } \\
\text { Finberg et al. } \\
\text { Present series (Case } 1 \text { ) }\end{array}$ & $\begin{array}{l}\ldots \\
\cdots \\
\cdots \\
\cdots\end{array}$ & $\begin{array}{l}\ldots \\
\cdots \\
\cdots \\
\cdots\end{array}$ & $\begin{array}{l}1956 \\
1959 \\
1963 \\
1963 \\
1963 \\
1966\end{array}$ & 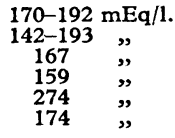 \\
\hline
\end{tabular}

Ward (1963) described the case of a patient suffering from overdosage with perphenazine and imipramine to whom $60 \mathrm{~g}$. of sodium chloride had been given to induce vomiting. Most of the salt was retained and the patient died after 24 hours, with a serum sodium level of $174 \mathrm{mEq} / 1$. Lesions in the brain were not described. Alexander and Wu (1935) discussed focal cortical scars and gliosis in the brains of patients dying from a variety of forms of dysentery and enterocolitis. They concluded that the lesions were due to an unspecified vascular cause, and briefly reviewed previous reports of similar lesions in a wide variety of febrile conditions. The latter could well have been associated with dehydration. Clinical accounts of the symptoms and signs of dehydration have also been given by Dodge et al. (1962) and Githens (1963).

A further condition in which dehydration and hypertonicity of the body fluids is of clinical importance is heat-stroke. Malamud, Haymaker, and Custer (1946) described pathological findings in the brains of 40 cases of heat-stroke and noted acute changes, cerebral oedema (brain weights were increased up to 1,493 g.), and haemorrhages around the third and fourth ventricles. After 24 hours there was loss of neurones from the cerebral cortex and basal ganglia and a commencing glial reaction. The possible importance of mechanical swelling of the brain in the causation of damage is suggested by the presence of cerebral oedema in the cases of Mérei (1960) (brain weight 1,580 g.) and of Ludwig (1963, Case 1) (brain weight 1,940 g.). Oedema was also noted in Case 6 of the series of seven cases of dehydration in infants due to diarrhoea reported by Skinner and Moll (1956). It is now a commonplace therapeutic manœuvre to treat such disorders as cerebral oedema and incipient acute renal failure by the intravenous or intragastric administration of a hypertonic solution. We have been unable to find any reports of brain damage in such patients which has resembled that described above. Such patients are usually given smaller amounts of solute than were our patients, and their fluid balance is controlled more carefully. Perhaps these factors might account for the lack of reports of brain damage, and if lesions have been observed they may well have been attributed to the primary disease and not to the treatment.

Neither naturally occurring diseases in animals nor experiments have produced morbid anatomical lesions resembling those described in this paper. There are many reports of a disease in pigs called "eosinophilic meningo-encephalitis," which is due to hypernatraemia and dehydration. In this condition there are diffuse cerebral cortical necroses and perivascular infiltration by polymorphs and eosinophils (Innes and Saunders, 1962). In no account of it is there a description of a pattern of lesions comparable to that found in human beings. In the laboratory subdural and subarachnoid haemorrhages have been found in several species of animals after intravenous or intraperitoneal injection of hypertonic solutions of urea, dextrose, or saline (Girard, 1956 ; Finberg, 1959 ; Luttrell, Finberg, and Drawdy, 1959 ; Rush, Finberg, Daviglus, and Cheung, 1961). The intracerebral lesions described by these authors have been punctate haemorrhages in both the grey and the white matter of the cerebral hemispheres and 
crebellum. Luttrell et al. (1959) also mention cortical damage, especially in the depths of the sulci, where there was failure of staining of neurones and many pyknotic nuclei were seen.

All these experiments have been of too short a duration for reliable histological signs of the necrosis to have occurred, although E.E.G. records have suggested acute cortical damage (Sotos, Dodge, Meara, and Talbot, 1960). In these experiments it has been shown that, although the systemic blood-pressure may fall, cerebral damage occurs even if it is kept constant (Rush et al., 1961). Luttrell et al. (1959) also confirmed the role of mechanical displacement of the brain in causing cerebral damage after dehydration. In their experiments lesions in the brain were completely prevented by the intracisternal injection of sufficient isotonic saline to maintain cerebrospinal fluid pressure at a normal level.

\section{Conclusion}

We consider that the cerebral infarction found in the present cases was due to a combination of arterial compression secondary to cerebral oedema, and, perhaps, to some more direct effect of the hypertonic state on sensitive structures. It is also possible that systemic arterial hypotension and anoxia may have aided the production of the diffuse cortical damage noted both in these patients and in the somewhat similar cases reported by Alexander and Wu (1935), Crome (1952), and Hallevorden and Meyer (1956).

Csapo (personal communication, 1964) and Fuchs (personal communication, 1964) state that they and others have used the amniotic-fluid-replacement technique in several thousand patients without any catastrophic results, although Wagatsuma (1965) reported at least 25 deaths following its use in Japan. The explanation for the difference between their findings and our cases is not certain. It is possible that a larger amount of hypertonic saline was injected into the first patient than is usually employed and that less amniotic fluid had been left behind to dilute it. As none of the injected fluid was available for analysis the actual concentration of sodium chloride used could not be checked. It is also possible that some of the hypertonic saline was injected not into the amniotic cavity but directly into the maternar circulation via the enlarged blood-vessels in the placental bed. If this had happened concentrated saline could have reached the brain directly via Batson's vertebral venous plexus. Against this are the delays of two and four hours before definite signs of brain damage appeared. These intervals are comparable with those observed in animal experiments after the intraperitoneal injection of hypertonic solutions, and are considerably longer than those found after intravenous injections (Sotos et al., 1960 ; Dodge et al., 1962). Although it is less valuable as evidence, the lack of histological damage to the spinal cord and extradural spinal veins also argues against the possible role of Batson's plexus.

We consider that the amniotic-fluid-replacement technique for inducing abortions should be used with caution until further information is available of any potential danger to the mother of the hypertonic state of the body fluids which it may induce. The same problem applies to any therapeutic use of hypertonic solutions for other purposes. As reviewed by Sotos et al. (1960), Ward (1963), and Githens (1964), the basic treatment of this disease of blood hypertonicity is the parenteral administration of suitable hypotonic fluids. In an emergency it might be helpful to try the manœuvre employed experimentally by Luttrell et al. (1959) and to inject saline into the cisterna magna (or perhaps by an ordinary lumbar puncture) to maintain a normal C.S.F. pressure.

\section{Summary}

Two cases are described of 20-year-old women in whom abortions were induced by the intra-amniotic injection of hypertonic sodium chloride solution. Both patients died with acute haemorrhagic infarction of the amygdaloid nuclei and adjacent structures and a Y-shaped infarct in the pons.

From other human cases and animal experiments it is suggested that the cerebral damage was due to excessive dehydration of the brain caused by the intra-amniotic injection of the strongly hypertonic solution.

It is suggested that the amniotic-fluid-replacement technique for inducing abortions should be used with care so as to avoid the production of excessive hypertonicity of the mother's circulation.

ADDENDUM.-Since the submission of this paper one of us (J.M. C.) has been involved with a further case. The almost identical history and post-mortem and microscopic findings were found in a 23-year-old woman following amniocentesis. This case will be discussed in detail at a later date.

We are grateful to H.M. Coroners, Drs. A. G. Davies and R. I. Milne, for permission to report these two cases. We wish to thank Professors F. E. Camps and I. Doniach and Dr. H. Urich for their advice on the preparation of this paper.

\section{REFERENCES}

Alexander L., and Wu, T. T. (1935). Arch. Neurol. (Chic.), 33, 72. Browder, J. (1930). Amer. F. Surg., 8, 1213.

Crome, L. (1952). Arch. Dis. Childh., 27, 468.

Csapo, A. (1961). In Progesterone and the Defence Mechanism of Pregnancy, edited by G. E. W. Wolstenholme and M. P. Cameron, p. 3. Churchill, London.

Cushing, H., and Foley, F. E. B. (1920). Proc. Soc. exp. Biol. (N.Y.),

17, 217. and Rabe, T. (1962). Trans. Amer. neurol. Ass., 87, 33.

Finberg, L. (1959). Pediatrics, 23, 40.

Kiley, J., and Luttrell, C. N. (1963). f. Amer. med. Ass., 184, Girard, $\mathrm{F}$

(1956). Acta pediat. (Uppsala), 45, 618

Hallevorden, J., and Meyer, J. E. (1956). In Handbuch der speziellen pathologischen Anatomie, edited by $O$. Lubarsch, F. Henke, and R. Rössle, section 13, vol. 4, p. 211. Springer, Berlin.

Innes, J. R. M., and Saunders, L. Z. (1962). In Comparative Neuropathology, p. 707. Academic Press, London.

Lindenberg, R. (1955). F. Neuropath. exp. Neurol., 14, 223.

Ludwig, J.' (1963). Schweiz. med. Wschr., 93, 705.

Luttrell, C. N., Finberg, L., and Drawdy, L. P. (1959). Arch. Neurol. (Chic.), 1, 153.

Malamud, N., Haymaker, W., and Custer, R. P. (1946). Milit. Surg., 99, 397.

Mérei, F. T. (1960). Dtsch. Z. Nervenheilk., 181, 174.

Métraux, H. R., and Binswanger, U. (1963).'Schweiz. med. Wschr., 93,

Meyer, A. (1963). In Greenfield's Neuropathology, edited by W. Blackwood, W. H. McMenemey, A. Meyer, R. M. Norman, and Dorothy S. Russell, 2nd ed. Arnold, London.

Beck, E., and Shepherd, M. (1955). 7. Neurol. Neurosurg. Psychiat., 18, 24.

Milles, G., and Hurwitz, P. (1932). Arch. Surg., 24, 591.

Nash, F. P., Orth, G., and Smolik, E. A. (1965). f. Neurosurg., 22, 264.

Peel, J. (1933). Quoted by Peel, J. (1962). Brit. med. 7., 2, 1397.

Rosomoff, H. L. (1962). F. Neurosurg., 19, 859.

Rush, B. F., Finberg, L.., Davigbus, G. F., and Cheung, C.-S. (1961). Surgery, 50, 359.

Skinner, A. L., and Moll, F. C. (1956). Amer. 7. Dis. Child, 92,

S62. 20, 293.

Sotos, J. F., Dodge, P. R., Meara, Patricia, and Talbot, N. B. (1960). Pediatrics, 26, 925 .

Stubbs, J., and Pennybacker, J. (1960). Lancet, 1, 1094.

Wagatsuma, T. (1965). Amer. 7. Obstet. Gynec., 93, 743.

Ward, D. J. (1963). Brit. med. F., 2, 432.

Weed, L. H., and McKibben, P. S. (1919-20). Amer. f. Physiol., 48,

Wood, C., Booth, R. T., and Pinkerton, J. H. M. (1962). Brit. med. Y., 2, 706. 